\title{
Case report. Het verwijderen van een penoscrotale ring na scrotuminfusie
}

\author{
Raya C. C. Ramdin' - Ilse M. Groenendijk · René Raaijmakers²
}

Published online: 21 March 2018

(c) The Author(s) 2018. This article is an open access publication.

\section{Samenvatting}

Deze casus betreft een patiënt die zich op de Spoedeisende Hulp (SEH) presenteerde met een rood, gezwollen scrotum en een penoscrotale ring na scrotuminfusie met fysiologisch zout, enkele dagen daarvoor. Scrotuminfusie en -inflatie zijn vormen van ongewone seksuele activiteit waarbij men lucht of een gassoort, respectievelijk vloeistof injecteert in het scrotum. In deze casus was door zwelling van het scrotum de penoscrotale ring niet meer door de patiënt zelf te verwijderen. De van industrieel metaal vervaardigde penoscrotale ring werd middels hydraulisch gereedschap door de brandweer verwijderd, zonder enige schade aan de huid toe te brengen.

Trefwoorden scrotuminfusie $\cdot$ scrotuminflatie $\cdot$ penisring $\cdot$ hydraulisch gereedschap

\section{Case report. Removing a penoscrotal ring after scrotal infusion}

\begin{abstract}
A patient visited our emergency room with a red, swollen scrotum and a penoscrotal ring after scrotal infusion with saline. Scrotum inflation or scrotum infusion is an unusual sexual activity in which one injects the scrotum with physiological saline solution, air, or other kind of gas. Because of the edematous scrotum this ring was, even after a few days not removable by the patient himself. This industrial penoscrotal ring was removed with hydraulic tools of the fire department without any damage to the skin.
\end{abstract}

Keywords scrotum infusion $\cdot$ scrotum inflation $\cdot$ penoscrotal ring $\cdot$ hydraulic tools

\section{Introductie}

Een bekende seksuele handeling is het aanbrengen van een penisring om een erectie te bevorderen. Deze wordt ook vaak gebruikt in combinatie met een vacuümpomp. Doorgaans betreft het een elastische ring. Wereldwijd zijn er meer dan 100 case reports gepubliceerd over mogelijke complicaties die optreden bij gebruik van een penisring en de behandeling van die complicaties [1]. Vaak treden complicaties op wanneer andere cirkelvormige objecten worden gebruikt, zoals zegelringen, trouwringen of metalen indus-

\footnotetext{
drs. Raya C. C. Ramdin

r.panchoe-ramdin@erasmusmc.nl

afdeling Urologie, Erasmus MC, Rotterdam, Nederland

2 afdeling urologie, Admiraal de Ruyter Ziekenhuis, Goes, Nederland
}

triële ringen, in plaats van de elastische ringen die speciaal voor dit doel gemaakt zijn. Hoewel, voor zover bekend, in de meeste gevallen een penisring wordt gebruikt om de erectie te bevorderen, wordt voor dit doel, in zeldzame gevallen, een penoscrotale ring toegepast, welke zowel om de penis als om het scrotum wordt aangebracht. Waarom dit wordt gedaan, is vooralsnog onduidelijk. Penoscrotale beknelling is geassocieerd met complicaties, zoals huidlaceraties, oedeem, penisnecrose, testisnecrose, erectiele disfunctie, urethrale stricturen en soms zelfs sepsis met multiorgaanfalen, die zelfs tot de dood kan leiden [2-5].

Een minder vaak beschreven seksuele handeling is scrotuminfusie of -inflatie. Hierbij brengt men vloeistof of lucht in het scrotum middels een naald. In een enkel geval wordt scrotuminfusie of -inflatie toegepast in combinatie met een penoscrotale ring [6]. Het inbrengen van lucht of vocht in het scrotum brengt een aantal risico's met zich mee; onder andere cellulitis, emfyseem, embolie, en mogelijk fatale 
complicaties, zoals gangreen van Fournier of luchtembolie $[6,7]$. In dit artikel presenteren wij een casus van een man die zich presenteerde op de Spoedeisende Hulp (SEH) van ons ziekenhuis.

\section{Casus}

Een man van 46 jaar met een blanco voorgeschiedenis presenteert zich op de SEH met een rood, gezwollen en pijnlijk scrotum met een metalen penoscrotale ring rondom de basis van zijn penis en scrotum (fig. 1). Hij heeft drie dagen geleden bij zichzelf $750 \mathrm{ml}$ fysiologische zoutoplossing via een infuus met een vlindernaaldje in het scrotum laten lopen. Deze kit heeft hij via internet besteld. Dit doet hij vaker, maar deze keer heeft hij een van industrieel metaal vervaardigde penoscrotale ring gebruikt. De motivatie voor deze handeling is onduidelijk. Hij probeert dezelfde dag het scrotum ook weer leeg te laten lopen met behulp van het infuusnaaldje. De metalen ring krijgt hij echter niet verwijderd. Mictie gaat moeizaam en alleen onder de douche. $\mathrm{Na}$ drie dagen neemt de zwelling zelfs toe en drukt de ring diep in de huid, waar het laceraties veroorzaakt. Patiënt is niet bekend met allergieën. Hij gebruikt geen medicatie.

Wij zien een man met matige pijn; vitale functies zijn niet afwijkend. Geen koorts. Scrotum en genitaal: status na circumcisie en een piercing ter hoogte van het frenulum. Aan de basis van de penis en het scrotum is een stevige metalen ring te zien, met een geschatte dikte van twee centimeter. Penis, scrotum en os pubisregio zijn rood en oedemateus. Onder de ring is druknecrose zichtbaar. Laboratoriumonderzoek laat geen verhoogde infectieparameters zien.

Er wordt een echoscrotum gemaakt om draineerbare vochtcollecties en abcessen uit te sluiten. Op de echo is

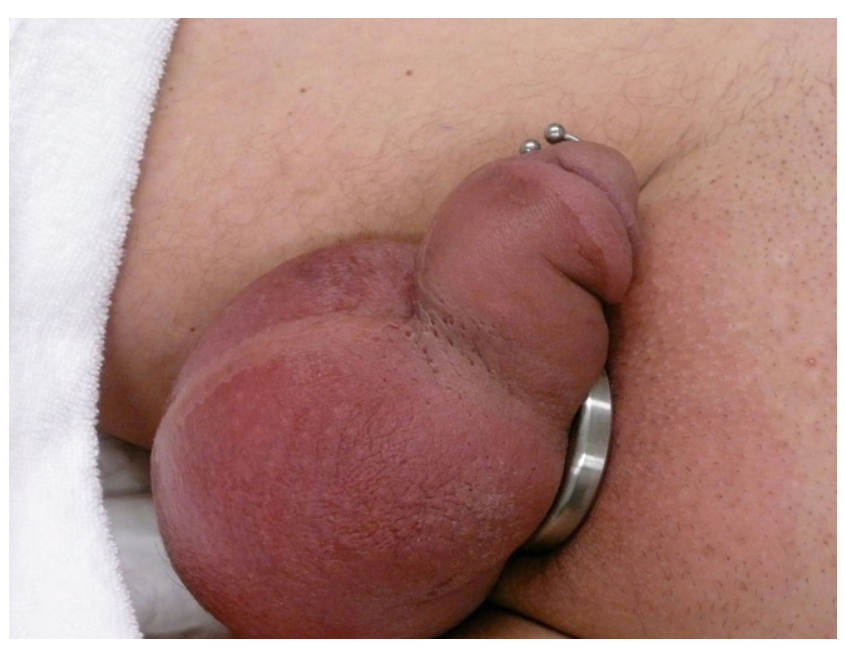

Figuur 1 Presentatie van de patiënt op de SEH een fors verdikte scrotumhuid te zien met het beeld van een cellulitis, maar geen vochtcollecties.

\section{Therapie}

Al snel wordt duidelijk dat de ring niet manueel of middels het instrumentarium dat op de SEH beschikbaar is, verwijderd kan worden. Patiënt geeft aan dat de ring is gemaakt van gehard staal en van industriële afkomst is. De grote uitdaging is om de ring te verwijderen met behulp van gereedschap zonder daarbij de huid van penis en scrotum verder te beschadigen. Er wordt besloten om de brandweer in te schakelen. Zij proberen om met een betonschaar de metalen ring door te knippen. Eerst wordt tussen huid en ring een houten tongspatel geplaatst ter bescherming van de huid (fig. 2). Maar de poging mislukt en de betonschaar raakt beschadigd. Uiteindelijk wordt met behulp van hydraulische knipper de metalen penoscrotale ring zonder problemen op twee plaatsen doorgeknipt, zonder enige schade toe te brengen aan omliggende huid (fig. 3).

De patiënt kreeg amoxicilline/clavulaanzuur IV 3dd 1,2 gram en adequate pijnstilling en werd ter observatie opgenomen. Een dag later werd hij in goede conditie ontslagen met nog een week amoxicilline/clavulaanzuur $3 \mathrm{dd}$ $625 \mathrm{mg}$. De scrotale zwelling en roodheid waren grotendeels verdwenen, maar de drukplek van de ring was nog zichtbaar (fig. 4). Bij poliklinische controle bleek dat hij er geen mictieklachten of seksuele beperkingen aan had overgehouden. Er is hem psychologische hulp aangeboden, waarvan hij geen gebruik heeft gemaakt.

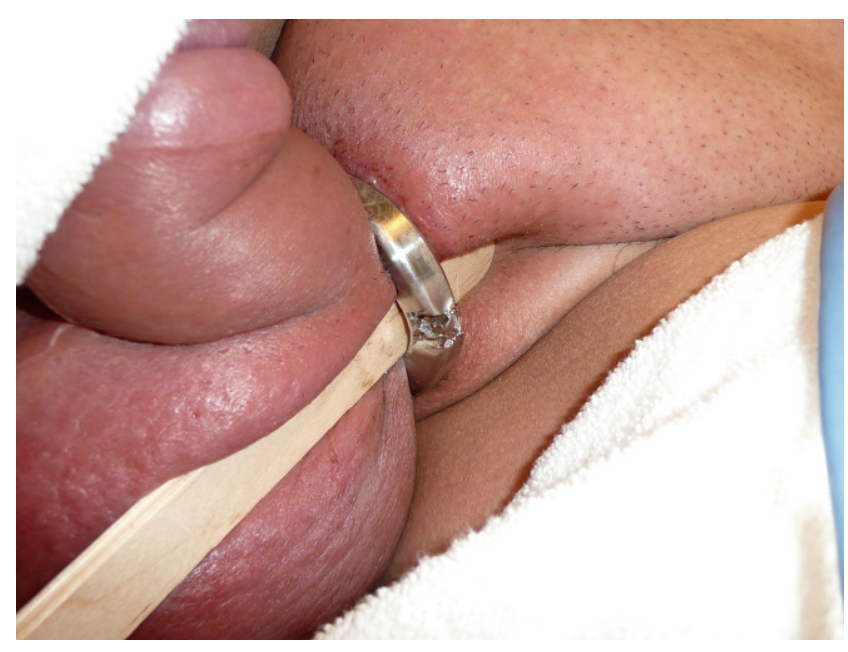

Figuur 2 Gebruik van de tongspatel 


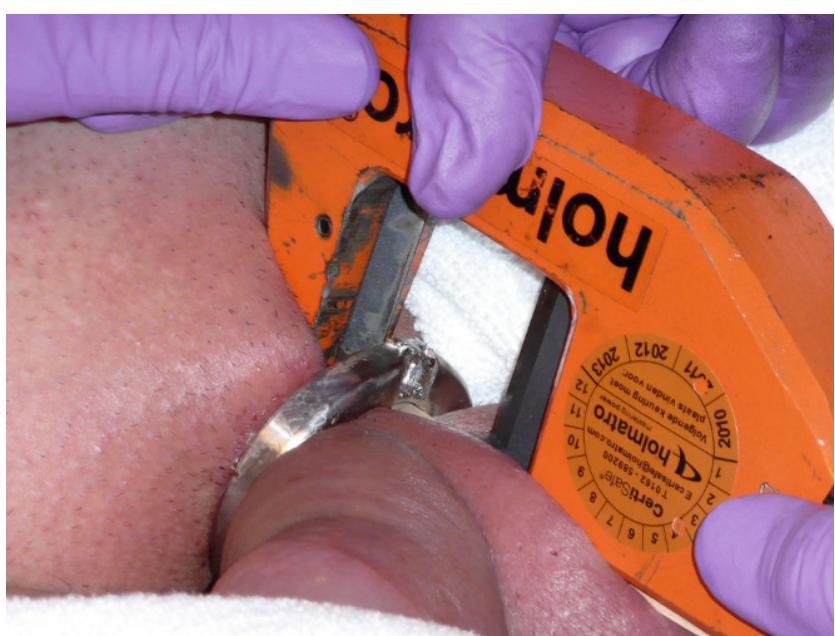

Figuur 3 Hydraulische knipper

\section{Discussie}

Wat de motivatie is om zelfstandig scrotuminfusie of -inflatie te verrichten, is onduidelijk; de handeling is niet altijd bedoeld ter ondersteuning van een erectie. Op internet zijn er verschillende beweegredenen te vinden om te experimenteren met dergelijke gevaarlijke handelingen. Voorbeelden hiervan zijn: een seksuele fetisj, een ander gevoel ervaren, uniek zijn, het geeft een 'shock'gevoel, om te bewijze dat het hun eigen geslachtsdeel is en dat ze er daarom mee kunnen doen wat ze willen of om een klein geslachtsdeel compenseren.

Er wordt al snel een verband gelegd met hyperseksualiteit, parafilie, erectiele disfunctie of psychiatrische ziekte, maar er dient per casus ingeschat te worden of de patiënt begeleiding of psychische hulp nodig heeft. Wel kan voorlichting gegeven worden over het veilig gebruik van seksuele hulpmiddelen en het volgen van een gebruiksaanwijzing.

In de literatuur zijn meerdere technieken beschreven voor het verwijderen van een ring op de operatiekamer, zoals de Winters-procedure voorafgaand aan de slingtechniek [2] en de Silk Winding methode [8], die echter alleen moet worden toegepast bij een penisring of het doorknippen, dan wel zagen van de ring met een orthopedisch instrument [1, 9].

Opmerkelijk is dat in eerdere case reports wordt gesproken over het gebruik van een roterende zaag, waarbij er grote kans is op schroeischade van de huid of andersoortig letsel [10]. Met een hydraulische knipper loopt de patiënt dit gevaar niet. De hydraulische knipper wordt door de brandweer onder andere gebruikt om gietijzeren pedalen door te knippen als iemand beklemd is geraakt bij een autoongeluk. Het knipstuk bestaat in dan uit een guillotinevormig snijdend deel. Ter bescherming van de huid gebruikten

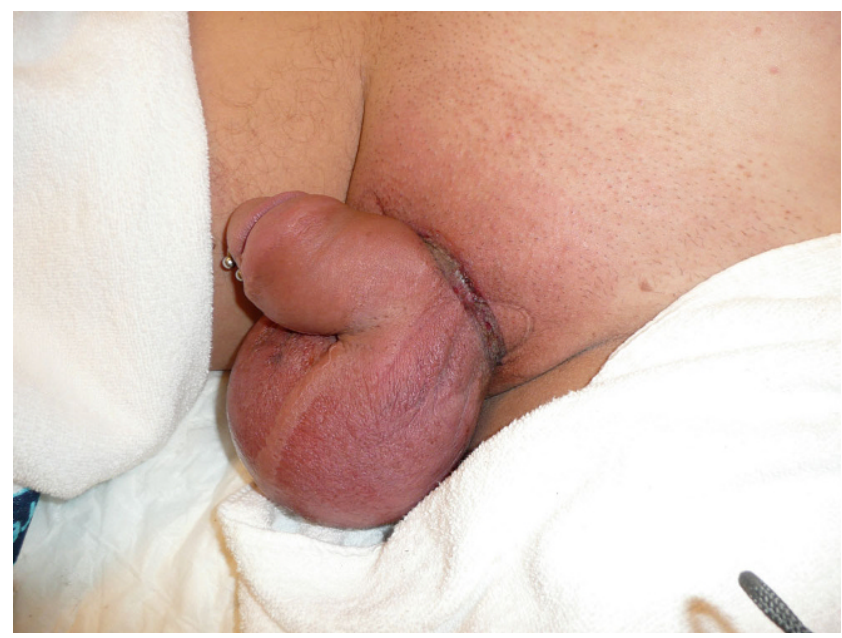

Figuur 4 Na verwijdering van penoscrotale ring

wij, net als bij de poging met de betonschaar, een tongspatel. De handpomp die de brandweer erbij gebruikte, werkte op olie en kon een maximale druk van 720 bar genereren, en een kracht overbrengen van 7,9 kiloNewton (d.i. 8,1 ton).

\section{Conclusie}

Er is in de literatuur veel geschreven over complicaties na het gebruik van een penisring, er is echter weinig bekend over complicaties met penoscrotale ringen en daarbij infusie of inflatie van het scrotum. Scrotuminfusie/-inflatie wordt in de praktijk meer toegepast dan we denken. Op internet staat veel uitleg over deze procedure, maar in de medische literatuur wordt niet beschreven hoe om te gaan met de complicaties hiervan. Denk bij niet manueel te verwijderen beknellende objecten rond de penis en/of het scrotum aan de lokale brandweer, nadat pogingen met de reeds in de literatuur beschreven technieken niet succesvol waren, of te riskant. Met behulp van hydraulische knipgereedschap kan het object makkelijk en veilig verwijderd worden, waarbij het risico op iatrogeen letsel van de genitaliën of omliggende weefsels verwaarloosbaar klein is.

Open Access This article is distributed under the terms of the Creative Commons Attribution 4.0 International License (http:// creativecommons.org/licenses/by/4.0/), which permits unrestricted use, distribution, and reproduction in any medium, provided you give appropriate credit to the original author(s) and the source, provide a link to the Creative Commons license, and indicate if changes were made.

\section{Literatuur}

1. Li C, Xu YM, Chen R, Deng CL. An effective treatment for penile strangulation. Mol Med Rep. 2013;8(1):201-4. 
2. Wu X, Batra R, Al-Akraa M, Seneviratne LN. Penoscrotal entrapment: a safe, innovative technique for removing metal constricting devices. BMJ Case Rep. Sep 25; 2012.

3. Detweiler MB. Penile incarceration with metal objects-a review of procedure choice based on penile trauma grade. Scand J Urol Nephrol. 2001;35(3):212-7.

4. Farooqui MR, Meena RS. Penile strangulation by metallic rings. Indian J Surg. 2011;73(5):359-60.

5. Ivanovski O, Stankov O, Kuzmanoski M, Saidi S, Banev S, Filipovski V, et al. Penile strangulation: two case reports and review of the literature. J Sex Med. 2007;4(6):1775-80.

6. Summers JA. A complication of an unusual sexual practice. South Med J. 2003;96(7):716-7.

7. Yoganathan KG, Blackwell AL. Unusual cause of acute scrotal cellulitis in an HIV positive man. Sex Transm Infect. 2006;82(2):187-8.

8. Dong C, Dong Z, Xiong F, Xie Z, Wen Q. Successful removal of metal objects causing penile strangulation by a silk winding method. Case Rep Urol. 2013;2013:434397. https://doi.org/10. 1155/2013/434397.

9. Chennamsetty A, Wenzler D, Fischer M. Removal of a penile constriction device with a large orthopedic pin cutter. Case Rep Urol. 2014;2014:347285. https://doi.org/10.1155/2014/347285.

10. Talib RA, Canguven O, Al Ansari A, Shamsodini A. Treatment of penile strangulation by the rotating saw and 4-needle aspiration method: two case reports. Arch Ital Urol Androl. 2014;86(2):138-9.

drs. Raya C.C. Ramdin aios urologie, afdeling Urologie, Erasmus MC, Rotterdam, Nederland

drs. Ilse M. Groenendijk anios urologie, afdeling Urologie, Erasmus MC, Rotterdam

dr. René Raaijmakers uroloog, afdeling urologie, Admiraal de Ruyter Ziekenhuis, Goes 